\title{
Sea ice volume and age: Sensitivity to physical parameterizations and thickness resolution in the CICE sea ice model
}

\author{
Elizabeth C. Hunke*
}

T-3 Fluid Dynamics and Solid Mechanics Group, Theoretical Division, Los Alamos National Laboratory, Los Alamos, New Mexico, USA

\section{Abstract}

New dynamics parameterizations in Version 5 of the Los Alamos Sea Ice Model, CICE, feature an anisotropic rheology and variable drag coefficients. This study investigates their effect on Arctic sea ice volume and age simulations, along with the effects of several pre-existing model options: a parameter that represents the mean cumulative area of ice participating in ridging, the resolution of the ice thickness distribution, and the resolution of the vertical temperature and salinity profiles.

By increasing shear stress between floes, the anisotropic rheology slows the ice motion, producing a thicker, older ice pack. The inclusion of variable drag coefficients, which depend on modeled roughness elements such as deformed ice and melt pond edges, leads to thinner ice and a more realistic simulation of sea ice age. Several feedback processes act to enhance differences among the runs. Notably, if less open water is produced mechanically

*MS-B216, Los Alamos National Laboratory, Los Alamos, NM 87545, 1-505-665-9852, fax 1-505-665-5926.

Email address: eclare@lanl.gov (Elizabeth C. Hunke*) 
through ice deformational processes, the simulated ice thins relative to runs with more mechanically produced open water. Thermodynamic processes can have opposing effects on ice age and volume; for instance, growth of new ice increases the volume while decreasing the age of the pack. Therefore, age data provides additional information useful for differentiating among process parameterization effects and sensitivities to other model parameters.

Resolution of thicker ice types is crucial for proper modeling of sea ice volume, because the volume of ice in the thicker ice categories determines the total ice volume. Model thickness categories tend to focus resolution for thinner ice; this paper demonstrates that 5 ice thickness categories are not enough to accurately resolve the ice thickness distribution for simulations of ice volume.

Keywords: Sea Ice, Rheology, Resolution, Volume, Age, Arctic

\section{1. Introduction}

2 As sea ice ages, particularly as it passes through its first melt season, 3 important physical properties change. For instance, sea ice desalinates via 4 flushing of melt water through permeable brine networks, and deformational 5 processes increase ice thickness through ridge-building. Freshening and thick6 ening both enhance the probability that sea ice will survive another melt sea7 son, simply by requiring more heat to melt it (Vancoppenolle et al., 2009a). 8 Conversely, the loss of perennial ice accelerates as younger, thinner ice re9 places it.

10 Decline of sea ice volume in the Arctic over recent decades, and an as- 
widely recognized (e.g., Kwok et al., 2009; Stroeve et al., 2012). The rapidity and magnitude of these ongoing changes present challenges for Arctic people and wildlife, as well as significant weather repercussions in lower latitudes (e.g, Francis et al., 2009; Screen, 2013). On the other hand, a seasonal ice pack implies simpler logistics for Arctic Ocean commerce and resource extraction, generating safety concerns along with a stronger focus on improving seasonal-to-interannual sea ice predictions.

Armour et al. (2011) analyze the large-scale response of sea ice to climate forcing based on the seasonal partitioning and survivability characteristics of first-year and multiyear (perennial) ice. They employ a reduced model for theoretical guidance in interpretation of an age related tracer available in CICE, namely the first-year ice area. Among their conclusions, they find that the climatological seasonal cycle of sea ice area and volume can be modeled accurately without correctly representing the proportions of first-year and multiyear ice area and volume, with negative consequences for capturing sea ice sensitivity to future climate change. They suggest that to improve models' projections of trends in sea ice area and volume, data/model comparison of the fractions of first-year and multiyear ice that survives melt and growth seasons would be particularly useful. Fortunately, sea ice age can be deduced from satellite observations. For example, Fig. 1 shows age estimates for the final week of 2009 (Maslanik et al., 2007, 2011; Tschudi et al., 2010).

In the present study, sea ice volume and age estimates from satellite observations are compared with model output. Following the work of Hunke and Bitz (2009), who look at how sea ice age evolves in a 1958-2006 CICE hindcast simulation, the analyses here use the chronological ice age rather 
than first-year ice area. I apply a newer version of the model than that of Hunke and Bitz (2009), but in a very similar grid and forcing configuration, to explore how parameterizations of physical processes and thickness resolution affect the simulation of both ice age and volume. As Armour et al. (2011) suggest, sea ice age provides useful information for discriminating among the sea ice processes tested.

Several factors affect the age of sea ice and how it evolves. Most important, of course, is the incessant march of time, chronologically aging the ice by an increment $\Delta t$ for every $\Delta t$ of time that passes. Thermodynamic processes can cause the pack ice to become younger on average, as new ice freezes and grows or as older ice melts and disappears. Similarly, when younger ice melts, the pack ice grows older at a rate faster than by chronological aging alone. These changes in ice age are evident in model simulations, such as that shown in Fig. 2. During the cold months of the year, the ice pack tends to grow younger (in the absence of chronological aging), while in the warm months it ages markedly. The largest rates occur in July (summer melting) and October (fall freeze-up) in the Arctic. Dynamic sea ice processes such as transport and deformation can not change the total age or volume of the ice pack, but they do move ice of various ages around the physical domain, affecting the spatial patterns of ice age and volume.

Hunke (2010) tunes an earlier version of the CICE model based on submarine Upward Looking Sonar measurements of ice draft, by altering parameters known to strongly affect sea ice thickness while maintaining albedo values close to observational estimates. One conclusion of that study was that similar spatial patterns of ice thickness, area and total ice volume could 
be obtained using different combinations of model parameters, evidence that the model retains sufficient flexibility to simulate observed conditions, but perhaps not with the proper balance of active and important processes, as suggested by Armour et al. (2011). In a detailed study of uncertainty in their sea ice-ocean model that includes assimilation of ice concentration and sea surface temperature, Schweiger et al. (2011) find that uncertainties in both model results and measured data exhibit wide ranges, calling for better characterization of measurement biases and additional work to understand and remedy systematic modeling errors. The purpose of this paper is not to tune the CICE model to observed data, but instead to highlight and explain the effects of some model options and processes that contribute to modeling uncertainties. This information will better constrain future tuning exercises of CICE and similar sea ice models, in stand-alone and coupled configurations, to better match observations of sea ice thickness and age.

An additional purpose of this paper is to introduce, in a unified framework, results from several new physical parameterization options available in CICE version 5, including anisotropic rheology, variable drag coefficients, and vertical resolution of the temperature and salinity profiles in a new "mushy layer" thermodynamic component. These options have been tested and documented in disparate configurations. The common framework used here allows a straight-forward comparison.

A brief outline of the new parameterizations and pertinent numerical configuration is provided in section 2, observational data descriptions in section 3, and model-data comparisons plus explanations of the parameterizations' effects in section 4 . Feedback mechanisms that operate between ther- 
modynamic and dynamic processes enhance changes due to parameterization differences, as expected, and also those changes associated with numerical resolution of the ice thickness distribution, described in section 5. Along with a discussion of the physical process results, section 6 concludes that the current thickness discretization is insufficient for resolving sea ice age and volume.

\section{Model Description}

The Los Alamos Sea Ice Model, CICE, is applied in its standard configuration and with selected adjustments to parameterizations. A complete description of the model can be found in Hunke et al. (2013b); here I present an overview of the features pertinent to this paper. The standard configuration includes a "mushy" thermodynamic model that prognoses both temperature and salinity in 7 vertical layers (Turner et al., 2013), the elastic-viscousplastic (EVP) dynamics scheme for computing ice velocity and deformation (Hunke and Dukowicz, 1997, 2002; Hunke, 2001), and mechanical redistribution (Thorndike et al., 1975; Rothrock, 1975; Lipscomb et al., 2007) using a 5-category ice thickness distribution (ITD). CICE version 5 includes options to use a form-drag parameterization (Tsamados et al., 2014) in place of the standard CICE drag coefficients and an elastic-anisotropic-plastic (EAP) rheology (Wilchinsky and Feltham, 2006; Tsamados et al., 2013) instead of EVP. I explore the effects of these two options on ice volume and age, along with sensitivity to the mean cumulative ridging area and to resolution of both the ice thickness distribution and vertical temperature and salinity profiles within the ice. 
In the standard CICE configuration, the ocean drag coefficient and atmospheric neutral drag coefficient are constant. The atmospheric drag coefficient over each ice thickness category is then adjusted based on Monin-Obukhov theory, accounting for the stability of the atmospheric boundary layer, during the surface flux balance calculation that determines the turbulent fluxes. (Hunke et al., 2013b). The new form drag parameterization adjusts the initial, neutral drag coefficients to account for structural disruptions to the flow of air or water past the ice, including ridges and keels, melt ponds and floe edges (Tsamados et al., 2014), prior to further adjustments for the surface flux balance.

The EAP rheology (Wilchinsky and Feltham, 2006; Tsamados et al., 2013) relates the internal ice stress tensor to the geometrical properties and orientation of underlying, virtual, diamond shaped floes. Local anisotropy of the sea ice cover is accounted for by an additional "structure" tensor, which includes processes that tend to make the ice cover more isotropic (e.g., thermal cracking, melting, and freezing together of floes), along with a function that determines ice floe re-orientation due to fracturing under axial splitting, biaxial tension, and biaxial compression. Geometry of the underlying diamonds alters the closing rate under convergence, and therefore the area loss rate due to ridging must also be changed for consistency with EAP. Elasticity is added in the EAP approach to create an efficient numerical algorithm, as in EVP.

Once the ice velocity and deformation rates are calculated using EVP or EAP, mechanical redistribution of the modeled sea ice occurs in two steps (Thorndike et al., 1975). First, a participation function defines which portion 
of the ice thickness distribution participates in ridging. The second piece is a redistribution function, which describes how the ice participating in ridging is redistributed among other thickness categories, based on the initial thickness and the desired height-to-area ratio of the ridge (Hunke, 2010). CICE assumes an exponential distribution of ridge thicknesses, consistent with observations of thick ice (Lipscomb et al., 2007). Following Rothrock (1975), sea ice strength is assumed proportional to the change in ice potential energy per unit area of compressive deformation.

The standard CICE configuration specifies 5 categories that describe the areal concentration of ice within each of the 5 thickness ranges, for each grid cell. The upper boundary for category $n$ is given by the recursive formula ("STD")

$$
\begin{aligned}
h_{B}(n) & =h_{B}(n-1) \\
& +\frac{3}{N}+\frac{45}{N}\left(1+\tanh \left[2\left(\frac{n-1}{N}-1\right)\right]\right)
\end{aligned}
$$

where $N$ is the total number of categories and $h_{B}(0)=0$. CICE includes an alternative method for assigning category boundaries based on the World Meteorological Organization (WMO) classification descriptors for sea ice. These thickness ranges are shown in Fig. 3 and Table 1 for the resolution cases studied in section 5 . In addition, I perform a sensitivity test for vertical resolution of the thermodynamic calculation, using 4 layers instead of 7 .

Age is carried in the model as a volume-weighted tracer, transported with the ice according to the conservation equation

$$
\frac{\partial\left(v_{n} T_{n}\right)}{\partial t}+\nabla \cdot\left(v_{n} T_{n} \mathbf{u}\right)=0
$$

where $v_{n}$ is the ice volume in thickness category $n, T_{n}$ is the tracer quantity 
in category $n, \mathbf{u}$ is ice velocity and $t$ represents time. Although aging does change physical characteristics of sea ice over time, here I assume that the age tracer is passive; i.e. it does not affect the physical evolution of the ice pack. The age tracer is initialized at age 0 upon freezing in open water and increases by the length of the time step at each step. Neither melting nor basal freezing alters the age of an ice column (thickness category), although the mean age of all ice in a grid cell may change as new ice appears or older ice disappears. As the ice pack advects and ridges, the age of ice in any given grid cell and thickness category is altered in a conservative manner following changes in ice volume. Thicknesses shown here are mean values over the grid cell, $h=\sum_{n=1}^{N_{c a t}} h_{n} a_{n}$, and category age quantities are merged using volume weighting

$$
T=\frac{\sum_{n=1}^{N_{c a t}} v_{n} T_{n}}{\sum_{n=1}^{N_{c a t}} v_{n}} .
$$

The CICE model and forcing are applied using a $1^{\circ}$ model configuration, as described in Hunke (2010) and Hunke et al. (2013a), but using an updated model version (CICE version 5.0.4). The thermodynamic slab-ocean mixedlayer model in CICE computes SST based on the surface energy balance of fluxes through the sea-ice and open-water interfaces. Modified NCEP forcing (CORE-II, Griffies et al., 2009; Large and Yeager, 2009) is applied for the wind, air temperature and humidity, for 1958-2009 as in Hunke et al. (2013a). Precipitation (Griffies et al., 2009), cloud fraction (Hunke and Holland, 2007) are provided as monthly mean climatologies. Ocean forcing fields (sea surface currents, slope, salinity, and deep ocean heat flux) are 20-year-mean climatologies from a Community Climate System Model (CCSM) climate 
run (b30.009, Collins et al., 2006). In addition to SST, the turbulent heat fluxes, wind stress, downwelling longwave radiation and shortwave radiation are computed as described in Hunke and Holland (2007) and Hunke (2014). Except for downwelling shortwave radiation, these fields also depend on the state of the ice. Although air temperature is provided as an input data set, it is adjusted in the presence of sea ice to reduce warm-temperaturepreconditioning for ice melt: if there is at least 10\% sea ice cover in a grid cell, then the air temperature is not allowed to be greater than $0.5^{\circ} \mathrm{C}$ (Hunke and Holland, 2007).

The model is run for 52 years (1958-2009) for the control and all resolution tests. Sensitivities to parameterization changes are tested by branching from the control simulation on 1 Jan 1990 and running for 20 years (Table 2). Results for December 2009 are analyzed, along with some multidecadal averages. In December, the ice concentration is nearly 100\% in the Arctic Ocean and the ice extent is similar to that in other runs, due to the climatological ocean forcing (Hunke and Bitz, 2009), simplifying comparison of the total ice volume, mean thickness and age across runs. Moreover, a thickness snapshot represents the time-integral effect of all processes determining the ice thickness distribution up to that time.

\section{Data Description}

Simulated sea ice thickness and age are compared with in situ and derived observational data from satellite, submarine, mooring and airborne sources. As described by Kwok et al. (2009), ice thickness estimates from the Ice, Cloud, and land Elevation Satellite (ICESat) are estimated by comparing 
returns from the ice or snow surface with that from a sea surface reference within the satellite footprint. The sea surface elevation reference is determined using new openings in the ice where possible, otherwise using returns where reflectivities are less than the snow-covered ice background reflectivity and/or where elevations are lower. In addition, the sea surface elevation is adjusted for biases associated with snow on thin ice and heterogeneous ice coverage within the satellite footprint. Comparison of the sea surface with ice/snow returns results in a freeboard estimate which is then converted to ice thickness, assuming constant sea water and ice densities and a seasonally varying snow density (Kwok and Cunningham, 2008). Snow thickness is estimated using precipitation rates falling onto an advecting ice cover whose motion is estimated from satellite passive microwave observations (see Kwok et al., 2009, for further information). Propagation of uncertainties in the variables used to compute thickness yield a total uncertainty (1 standard deviation) of $0.7 \mathrm{~m}$ in the ICESat thickness estimates (Kwok and Cunningham, 2008), and differences in sea ice draft with mooring and submarine profiles agree within about $0.5 \mathrm{~m}$ (Kwok et al., 2009).

Other observational data sources for 1990-2009 (submarine upward-looking sonar, moorings, IceBridge flights and coastal measurements) were obtained from the Unified Sea Ice Thickness Climate Data Record (Lindsay, 2013). This data set consists of thickness measurements from numerous sensors and sources, each with its own sampling issues and accuracy estimates (or lack thereof). The data are collected in a common format with added summaries calculated for time (1 month) and length $(50 \mathrm{~km})$ scales comparable to typical model output. Submarine and moored upward-looking-sonar measurement 
errors are typically of order $25 \mathrm{~cm}$ (Lindsay, 2010). Thickness uncertainties in the IceBridge airborne data range up to $0.51 \mathrm{~m}$.

Sea ice age can be deduced from satellite observations using various approaches. Here I use ice age data provided by the Sea Ice Prediction Network (http://nsidc.org/data/sipn/data-sets.html; Maslanik et al., 2007, 2011; Tschudi et al., 2010). Using satellite and buoy data for ice motion, individual sea ice parcels are tracked from the time they form until they disappear (via melt or transport out of the Arctic) at a spatial resolution of $12.5 \mathrm{~km}$ and a time step of 1 week. The age of a parcel is the age of the oldest ice within that parcel, thus biasing the data toward older ages during periods when large amounts of younger ice are present. If a parcel survives the summer melt season with an ice concentration of at least $15 \%$, then the parcel ages by 1 year (Maslanik et al., 2007, 2011; Tschudi et al., 2010). This derivation of ice age from satellite observations differs fundamentally from the modeled ice age, in that the model ages the ice volume within each thickness category chronologically on each time step and then combines the resulting "age content" into a single value per grid cell. Thus, modeled ice age is expected to be younger than the observational data, based on definition differences alone.

\section{Results: Physical Parameterizations}

Dynamical processes have a much larger effect on spatial patterns than do thermodynamic processes, which generally are smooth except near the ice edge. For instance, Fig. 4 shows that during December 2009, thermodynamic growth in the model increased the ice volume uniformly throughout the ice 
pack, with larger growth rates in coastal areas and substantial melting only along the ice edge in the North Atlantic. Dynamical volume rates of change during the same month take both positive and negative signs (Fig. 4c). This variation is loosely reflected in the rates of change of sea ice age (Fig. 4b, d). Generally speaking, this configuration of the CICE model produces ice that is too thin in the central and eastern Arctic Ocean and too thick near the northern Canadian and Greenland coasts, as evident in Fig. 5 and Table 3. Sea ice is thickest on the western side of the Arctic, north of Greenland and the Canadian Archipelago, due to convergence and ridging as the Transpolar Drift Stream transports ice from the eastern side and across the North Pole. Some of this ice exits the Arctic Basin through Fram Strait, carrying thick ice from Greenland's north coast into the Greenland Sea. Likewise, the Beaufort Gyre north of Alaska carries thicker ice into the Beaufort Sea. Fig. 5 shows ICESat ice thickness estimates (Kwok et al., 2007; Kwok and Cunningham, 2008; Kwok et al., 2009) for October/November campaigns compared with November control run output for 2005, 2006 and 2007. Prior to the drastic sea ice retreat event during the summer of 2007 , model thicknesses were comparable but slightly too thin on the eastern (Siberian) side of the Arctic Ocean. Propagation of uncertainties in the variables used to compute thickness yield a total uncertainty ( 1 standard deviation) of $0.7 \mathrm{~m}$ in the ICESat thickness estimates (Kwok and Cunningham, 2008); the model output is close to the lower end of this range. Comparison with other observational data sources for 1990-2009 (upward-looking sonar from submarine cruises, moorings, IceBridge flights and Canadian coastal measurements, Lindsay, 2013) shown in Table 3 (see Fig. 6 for locations), confirms that the simulated ice is 
too thick on the western side of the Arctic in the control run and too thin in the central Arctic (submarines, NPEO). Notably, these biases are opposite those reported for the PIOMAS sea ice-ocean model (Schweiger et al., 2011); PIOMAS uses NCEP-based atmospheric forcing and the Parallel Ocean Program (POP) as its ocean component, the same ocean model used to generate the ocean forcing used here (albeit in a very different configuration).

Figs. 7 and 8 show December 2009 simulated sea ice thickness and age for the control (CNTL) and 5 sensitivity runs, as listed in Table 2. Sea ice extending from north of Greenland to the North Pole is older in the control run than indicated by observations (Fig. 1). As we will see in the sensitivity results, thicker ice tends to be older but the relationship is not strictly proportional. Fig. 9a provides the budget of thermodynamic melting and growth terms that contribute to ice volume changes for each parameterization option tested, along with the differences for each term relative to the control run (Fig. 9b). Congelation growth (onto the bottom of existing sea ice) and bottom melting dominate the thermodynamic processes, roughly balancing each other; thus small changes in any of the terms relative to the two dominant terms can determine whether the ice pack grows or shrinks (see also Kwok and Untersteiner, 2011). Because these terms affect ice age in different ways, how they vary across runs also alters the age characteristics of the simulated ice.

The ridging parameterization bears on a sensitivity run that tests the effect of the mean cumulative thickness distribution of ice participating in ridging, $a^{*}$ ("astar", Fig. 7b). Within the participation function, illustrated in Fig. 10 for a uniform thickness distribution, a weighting function $b$ assigns 
relative weights to the ice thickness categories, so that thinner categories tend to contribute more of their area to ridge formation:

$$
b(h)=\frac{\exp \left[-G(h) / a^{*}\right]}{a^{*}\left[1-\exp \left(-1 / a^{*}\right)\right]}
$$

where the cumulative ice thickness distribution $G(h)$ is the fractional area covered by ice thinner than $h, G(h)=\int_{0}^{h} g(h) d h$, and $g(h) d h$ is the fractional area of ice with thickness in the interval $(h, h+d h)$. During convergence, open water closes first. Integrating $a_{P}(h)=b(h) g(h)$ between category boundaries, Eq. (2) implies that the mean value of $G$ for ice participating in ridging is $a^{*}$, and the area ratio of ice participating from each category $n$ (or open water closing, $n=0$ ) to the total area of ice ridging and open water closing is

$$
a_{P n}=\frac{\exp \left(-G_{n-1} / a^{*}\right)-\exp \left(-G_{n} / a^{*}\right)}{1-\exp \left(-1 / a^{*}\right)},
$$

where $G_{n}$ equals $G$ evaluated at the upper boundary of category $n$. For $n=0$ we take $G_{-1}=1$. The control run uses $a^{*}=0.05$, meaning that the thinnest $5 \%$ of the ice participates in ridging, on average.

In the sensitivity run, $a^{*}=0.1$. This increase in the value of $a^{*}$ shifts the ridging ice toward thicker categories; less of the very thin ice ridges. For instance with the 100-category participation function shown in Fig. 10, the same amount of $0.2 \mathrm{~m}$ ice will ridge in both cases, but $0.1 \mathrm{~m}$ ice makes up only $7 \%$ of the ridge with $a^{*}=0.1$, compared with $10 \%$ using $a^{*}=0.05$. Thus there will be a smaller volume of ice formed from $0.1 \mathrm{~m}$ ice with $a^{*}=0.1$, and similarly, a larger ridged ice volume formed from ice thicker than $0.2 \mathrm{~m}$. When thicker ice ridges, it tends to form lower ridges that cover a larger area (Hunke, 2010). Greater ice coverage means that less open water is available with $a^{*}=0.1$, initially allowing less new ice to freeze and subsequently be 
deformed into ridges. Over time, this reduces the total volume of ice, as evident in Figs. 7b and 11a; the thinner ice pack experiences a stronger melt rate during the summer. Fig. 9b shows a small decrease in the volume of frazil ice (new ice formed in open water), relative to the control run, which is large enough to account for the overall thinner ice pack. The other terms, increased congelation growth, decreased top melting and increased bottom and lateral melting, are consistent with a thinner ice pack and generally cancel each other out. The sea ice simulated with $a^{*}=0.1$ is thinner and younger (Fig. 11c) than in any of our other physical parameterization tests.

Activating the form drag parameterization results in thinner ice than in the control run (see Figs. 7c and 11a) and a pattern of ice age that is much closer to the observations (Fig. 1). In particular, the age pattern north of Greenland reflects the older ice near the coast, with younger ice farther north and an area of 3- to 4-year-old ice near the North Pole. Moreover, the band of older ice reaching westward in the Canadian Basin north of Alaska is more than 5 years old, as in the observations, and yet it is thinner than in CNTL. These differences result from changes to the stresses acting on the top and bottom surfaces of the ice, particularly sails and keels. Ridged ice is largely responsible for variations in the atmospheric and oceanic drag coefficients, although floe and melt pond edges also contribute in summer, and skin drag contributes throughout the year (Tsamados et al., 2014). Deformed (ridged) ice in the model is most concentrated in the thick ice areas north of Greenland (Hunke, 2010), increasing drag and accentuating the advection of ice into the Beaufort and Greenland Seas. Tsamados et al. (2014) attribute the overall decrease in sea ice volume to relative changes in the thermodynamic 
cycle of ice growth and melt, with increased melt rates dominating increased growth. However, Figs. 11a and 9b indicate the opposite in our runs, that a reduction in congelation and frazil growth rates and increased top melting in the form drag case accumulates a larger volume decrease than the increase due to changes in bottom and lateral melting and snow-ice formation. (Snow-ice formation results from the conversion of snow into ice when snow loading pushes the ice freeboard below sea level, resulting in flooding of the ice.) Tsamados et al. (2014) also show that the form drag parameterization increases ice speed in most areas north of Greenland and the Canadian Arctic, while decreasing drift in regions of thinner ice.

The anisotropic rheology (Fig. 8a) substantially increases ice thickness on the western side of the basin, leading to an older ice pack in that area. Changes to the rheology and form drag change the mean age of the entire ice pack noticeably only in summer (Fig. 11c), indicating that thinner, younger ice in other seasons dominates pack ice age in this average measure. As Tsamados et al. (2013) discuss, the modeled anisotropy increases the shear strength of the ice, reducing the ice drift. (They found that the total ice volume in their anisotropic test could be decreased to match that in their EVP case, while largely retaining the patterns of ice thickness and area seen in the anisotropic case, by adjusting the sea ice strength frictional energy dissipation parameter $C_{f}$.) In this case, Fig. 9b indicates that freezing reductions and increased top melt are not large enough to offset the increased ice volume due to decreased bottom melting and growth of snow-ice. Note that even though the difference in snow-ice formation is relatively small, it is enough to account for the net difference in ice volume between the CNTL 
and aniso runs.

Using both the form drag parameterization and the anisotropic rheology leads to a solution with characteristics of both (Fig. 9b, 11a). The anisotropic rheology tends toward thicker ice via reduction of bottom melting, while the form drag parameterization produces thinner ice, especially during winter, thus decreasing the amplitude of the ice thickness seasonal cycle throughout the year, compared with the control run.

Thickening and aging of ice in runs with the anisotropic rheology are strongly associated with the decrease in sea ice transport, as seen in the "halfU" case shown in Fig. 8b. Here, the sea ice velocity is computed using the standard EVP dynamics, but the resulting velocity components are divided in half for advecting the ice. Deformation rates used to compute the sea ice ridging rates are not changed, directly, although there are feedback effects that indirectly affect the ice volume as the ice slows down. For instance, reduced transport of ice out of the basin through Fram Strait increases the total amount of ice remaining in the Arctic Basin, leading to smaller areas of open water. With less ice melting in summer (due to smaller heat absorption by the ocean), the ice does not thin as much as in the control run. When this thicker ice deforms, the ridges tend to cover a greater area horizontally, further decreasing the amount of open water available for heat uptake. With less open water available to close and a greater volume of ice overall, the ice continues to slow down. Mean growth rates also decrease, but not enough to compensate for the reduced melt rates (Fig. 9b).

Finally, the "4lyr" sensitivity simulation illustrates the effect of the thermodynamic parameterization via its vertical resolution. The standard con- 
figuration of CICE version 5 includes a new thermodynamic model that prognoses sea ice salinity based on mushy layer theory (Hunke et al., 2011; Turner et al., 2013), with 7 layers in the ice. In prior versions of CICE, we used the thermodynamic model of Bitz and Lipscomb (1999), which solved for temperature using an assumed salinity profile and 4 layers. Decreasing the number of layers in the mushy formulation to 4 causes the ice to become thicker and older, as seen in Figs. 8c and 11b, d. (Because of the differing number of layers, this run could not be branched from the control run in 1990 and therefore was run for 1958-2009.) The additional layers in the control run better resolve the steep vertical temperature and salinity gradients near the top and bottom ice surfaces, allowing greater conductive fluxes and potentially more ice growth and melt. With fewer layers, Fig. 9d shows that top melting decreases dramatically relative to CNTL, offset somewhat by increased bottom and lateral melting, while decreased congelation and frazil growth ensues in winter. In one-dimensional tests, Turner et al. (2013) showed that simulations using 4, 10 and 100 layers can reproduce the character of measured vertical salinity profiles, but the drainage region near the ice-ocean interface is too thick when resolution is low. Because tracers such as heat, salt and biological content must be carried for each additional layer, we have chosen to use 7 layers in CICE version 5 as a compromise between vertical resolution and computational efficiency.

\section{Results: Thickness Category Resolution}

In their seminal work introducing an ice thickness distribution into a coupled climate model, Bitz et al. (2001) performed a number of simulations to 
study its effect, including how the number of categories affects the sea ice simulation and fluxes crucial for coupling the ice and ocean models. They found that 5 categories were sufficient for climate modeling purposes at that time; that is, the ice area, extent and fluxes were converged, including radiative fluxes that hinge critically on sea ice albedo. They noted that the sea ice volume was not converged with just 5 categories, but that this did not affect their coupled climate simulations significantly.

In subsequent tests, Holland et al. (2006) explored how a modeled sea ice thickness distribution affects polar climate in the context of the climate model CCSM3, comparing runs with different spatial resolutions (T42, T85) and different numbers of thickness categories $(1,5)$ in present-day and doubled $\mathrm{CO}_{2}$ scenarios. They did not consider other ITD discretizations better resolved than the 5-category case, however. The PIOMAS model and its predecessors (e.g., Zhang and Rothrock, 2003; Lindsay et al., 2009; Schweiger et al., 2011) uses 12 categories in an Eulerian framework with a fixed ice thickness assigned to each thickness category. The Eulerian approach will tend to be more diffusive than the Lagrangian ice thickness distribution approach used here, in which the ice thickness may vary within the bounds of each category (Bitz et al., 2001; Lipscomb, 2001).

Non-convergence of the ITD resolution using 5 categories is apparent in Fig. 11b and d, comparing the control run with STD 10, which uses 10 thickness categories (see Fig. 3). The spatial patterns shown in Fig. 12a reflect thicker and older ice in the 10-category case. Because Eq. (1) does not produce similarly bounded categories, to explore the thickness resolution issue I utilize a second option for setting the category boundaries based on 
the World Meteorological Organizations sea ice classification scheme. In the 5-category WMO case (WMO 5), 4 of the categories are less than $2 \mathrm{~m}$ thick, with the fifth category containing all ice thicker than $2 \mathrm{~m}$; the thinnest category contains ice up to $0.3 \mathrm{~m}$ thick (Fig. 3). The 6-category case (WMO 6) divides the thinnest category in half. A third case (WMO 5+), created for this study, is identical to the 5-category WMO case but adds a sixth category with ice up to $4.57 \mathrm{~m}$ thick, the largest category boundary in CNTL. None of the resolution runs could be branched from the control run; they were all initialized from a state of no ice in 1958 and run through 2009, like the control.

Because ice growth and melt rates and the participation function (Fig. 10) all exhibit the greatest variation for thinner ice (Thorndike et al., 1975), it stands to reason that increasing the resolution in this portion of the thickness distribution should matter. However, there is little difference between the WMO 5 and WMO 6 cases (they overlie each other in Fig. 11b, and their spatial patterns are so similar that WMO 6 is not shown in Fig. 12). Fig. 9d shows that in both cases, an increase in congelation growth and decrease in lateral melting is offset by increased melting at the bottom and top of the ice. In the higher-resolution WMO 6 case the increased congelation growth and decreased top melting are amplified, reflecting enhanced conduction in the thinnest ice category, which also leads to younger ice (Fig. 11d). Adding the category with ice between 2 and $4.57 \mathrm{~m}$ in WMO $5+$ thickens the ice considerably, such that the total ice volume (Fig. 11b) and the pattern of ice thickness (Fig. 12c) are very similar to the control run. Thermodynamically, the change occurs primarily in top and lateral melting, which are decreased 
and increased, respectively, relative to WMO 5. With more congelation growth and more bottom melting than in the control run, however, WMO $5+$ features generally younger ice than in the control, but older than in WMO 5 (Fig. 11d).

To further illustrate the importance of resolving thicker ice, Fig. 13a shows the differences in thickness for ice in categories 1 and 2 of the 10-category ITD minus that in category 1 of the 5-category case, and similarly for all ice in the remaining, thicker categories in Fig. 13b. Although the 10-category ITD resolves the thinner ice much better than does the 5-category (CNTL) ITD, the difference in the thinner ice thickness is relatively small. Most of the change in thickness noted between these simulations in Figs. 7, 11 and 12 occurs in the thicker categories.

This observation is borne out in the WMO tests, where the difference between WMO 5+ and WMO 5 appears in the thicker categories (Fig. 13d). The thinner categories have minimal differences (not shown). WMO $5+$ shows notable differences with CNTL in the thinner categories (Fig. 13c), but the thicker categories are very similar (not shown) and as a result, the basin-wide ice volume in these simulations are quite similar. The volume of ice in the thicker categories determines the total ice volume, and therefore the discretization of the thicker ice range is crucial for proper modeling of ice volume.

Thermodynamically, better resolution of thin ice increases heat conduction from the ocean to the atmosphere, which leads to increased congelation growth at the bottom of the ice column and increased melting at the top of the column, as illustrated in Fig. 9d. Lateral and bottom melting are both 
fueled largely by heat accumulated in open water, but they do not vary together in the model. In fact, they often show changes opposite in sign. The fraction of modeled ice that melts laterally is proportional to $\Delta T^{1.36}$ based on geometrical arguments (Maykut and Perovich, 1987; Steele, 1992), where $\Delta T$ is the difference in ocean and ice bottom temperatures. Bottom melting (and freezing), on the other hand, depends on the difference in heat flux to the bottom of the ice (proportional to $\Delta T$ ) and heat conduction within the ice, away from the interface. Differences in ice area and thickness among runs will therefore affect lateral and bottom melting in different ways. Fig. 9d shows that improving resolution of thicker ice tends to decrease bottom melting and increase lateral melting, while improving thin ice resolution decreases both top melting and frazil ice growth while increasing bottom melt and congelation growth. As Kwok and Untersteiner (2011) note, the residual balance of these processes determines whether the ice pack grows or shrinks, and we do not have sufficient data at this time to understand what the proper balance should be. However, since these processes also change the simulated ice age, age data can help constrain the model parameters.

\section{Discussion and Conclusions}

The CICE model was designed for use in large-scale climate simulations, which primarily require accurate representation of the surface fluxes' annual cycle. For this purpose, Bitz et al. (2001) found that 5 thickness categories were sufficient: ice area and critical ice-ocean fluxes were converged in their model. Sea ice volume was not converged, but they reasoned that this had only a modest effect on their coupled climate simulations. Since then, two 
major, relevant advances have occurred in this field of research: larger and more reliable ice thickness data sets have become available, and questions are being asked of climate models that require better simulations of ice thickness. For example, Holland et al. (2008) showed that future projections of seasonally ice-free conditions in the Arctic are sensitive to the initial mean and spatial distributions of ice thickness simulated by climate models, some of which do not resolve an ice thickness distribution at all. A major result of the present paper is the recognition that 5 ice thickness categories are not enough to accurately represent observed thickness data nor to properly model mechanical sea ice processes that control ice volume.

Prior to the drastic sea ice retreat event during the summer of 2007, the model simulations presented here resemble ICESat thickness data, but with a thin bias on the eastern side of the Arctic Ocean and a thick bias on the western side. The thick bias worsens after the 2007 minimum ice event. While resolution of thinner ice does affect its simulation, as shown in Fig. 13, the volume of ice in thicker categories determines the total ice volume, and therefore resolution of the thicker ice range is crucial for accurate representation of ice volume. Total ice volume in the WMO 5 and WMO 6 simulations, having identical ITDs except for ice thinner than $0.3 \mathrm{~m}$, are practically indistinguishable. Results from the WMO $5+$ test are more similar to CNTL because of the extra resolution of 2-4.5 $\mathrm{m}$ ice. In STD 10, resolution increases for both thin and thick ice, and ice volume shifts toward thicker ice in the central and eastern Arctic associated largely with a decrease in top melting (Fig. 9).

Even though the total volume and thickness patterns of WMO5+ and 
CNTL are quite similar, the age of the ice pack at the end of those simulations are notably different. Thus, ice age provides a practical data set that can be used to distinguish among parameterizations and, eventually, to tune model parameters. A prime example is the formdrag parameterization test, in which reduced or increased drag in different regions of the Arctic produce thinner ice overall, some being older and some younger than in CNTL. In this case, the inclusion of variable drag coefficients that depend on modeled roughness elements such as deformed ice and melt pond edges leads to a more realistic simulation of sea ice age.

Age is a volume-based tracer in CICE, which means that it is conserved under volume-conserving processes such as ridging. Alternatively, age could be tracked based on ice area, which would make comparisons with satellite observations more natural (Vancoppenolle et al., 2009b). Hunke and Bitz (2009) argue that age can not be considered an ice surface property in a fullphysics sea ice model. They included a test in which bottom (congelation) ice growth decreased ice age. This change makes the ice pack younger as a whole, but it has not been adopted for other runs because the converse effect, aging under melting conditions, can not be accounted for without tracking the age of individual layers of the vertical ice column. Lietaer et al. (2011) have proposed a new method for defining and tracking the vertical profile of ice age.

Age does not scale proportionally with thickness, because ridging ice thickens without commensurate aging and because thermodynamic sources and sinks of ice, namely growth in open water areas and complete melting of thinner ice, also cause ice age and volume values to diverge. Dynamic effects 
alter spatial patterns in ice age and volume, often initiating or modifying local or regional feedback mechanisms that enhance age and volume differences. For instance, in the formdrag simulation, sea ice rounding the Beaufort Gyre north of Alaska is both thinner and older than in the control run. This ice is older because of its origin north of Canada and Greenland, but it is moving faster because of increased drag, which tends to cause thinning via increased opening and melt rates (the opposite of the halfU case).

A negative feedback associated with ridging contributes to differences among several runs but is particularly evident in the astar simulation, in which ridging of thicker ice creates wider, shorter ridges with less open water available for new ice freezing (frazil), leading eventually to a thinner ice pack. As the ice thins and the ice-ocean albedo feedback becomes active, melting begins to predominate.

Thermodynamic processes are key to differences in both volume and age among runs. In particular, we see in the parameterization tests that bottom melting and congelation/frazil formation tend to act in concert to decrease or increase ice volume, often counteracted by top melt. The net effect is due to small differences in these large terms, which means that small terms like snow-ice formation and lateral melting can play an important role. Thermodynamic ice growth and melting act most vigorously in the thin ice range, altering ice volumes by small amounts that can build over time. In contrast, inaccuracy due to insufficient resolution of the ice thickness distribution quickly affects the larger volumes of thicker ice categories by altering the participation (and redistribution) of ice in those categories.

As the complexity of sea ice models escalates with the inclusion of ever 
more detailed processes, the need for more and better sea ice measurements from the field and laboratory compounds. Sea ice models contain many more parameters than can be constrained with currently available data, confounding validation efforts and lending doubt to modeled process fidelity. Increasing the number of degrees of freedom associated with higher resolution demands yet more data for model validation. Fortunately, the addition of new data types combined with a detailed comparison of fundamental processes can shed light on physical and model sensitivities to more complex processes and their controlling parameters. Sea ice age is such a data set, discriminating among the effects of parameterizations that are not easily distinguished in terms of ice area or volume alone. As indicated by the sensitivity tests presented here, selectively combining model parameterizations and suitably tuning their parameters have the potential to improve simulation fidelity of the fields for which we have reliable observational data while we wait for more discriminating data sets.

\section{Acknowledgments}

Sincere thanks to Matthew Hecht for providing comments on the manuscript. This work was performed within the Climate, Ocean and Sea Ice Modeling (COSIM) program at Los Alamos National Laboratory, as a contribution to the Sea Ice Prediction Network with funding from the Regional and Global Climate Modeling Program of the U. S. Department of Energy, Office of Science, Biological and Environmental Research Division. Los Alamos National Laboratory is operated by the National Nuclear Security Administration of the U.S. Department of Energy under Contract No. DE-AC52-06NA25396. 
Armour, K. C., C. M. Bitz, L. T., Hunke, E. C., 2011. Controls on Arctic sea ice from first-year and multi-year ice survivability. J. Climate 24, 23782390 .

Bitz, C. M., Holland, M. M., Weaver, A. J., Eby, M., 2001. Simulating the ice-thickness distribution in a coupled climate model. J. Geophys. Res.Oceans 106, 2441-2463.

Bitz, C. M., Lipscomb, W. H., 1999. An energy-conserving thermodynamic sea ice model for climate study. J. Geophys. Res.-Oceans 104, 1566915677.

Cavalieri, D., Parkinson, C., Gloersen, P., Zwally, H. J., 1996, updated 2009. Sea ice concentrations from Nimbus-7 SMMR and DMSP SSM/I passive microwave data, 1979-2009. Tech. rep., National Snow and Ice Data Center, Boulder, Colorado USA, digital media.

Collins, W. D., Bitz, C. M., Blackmon, M. L., Bonan, G. B., Bretherton, C. S., Carton, J. A., Chang, P., Doney, S. C., Hack, J. J., Henderson, T. B., Kiehl, J. T., Large, W. G., McKenna, D. S., Santer, B. D., Smith, R. D., 2006. The Community Climate System Model Version 3 (CCSM3). J. Clim. 19, 2122-2143.

Francis, J. A., Chan, W., Leathers, D. J., Miller, J. R., Veron, D. E., 2009. Winter northern hemisphere weather patterns remember summer Arctic sea-ice extent. Geophys. Res. Lett. 36, L07503, doi:10.1029/2009GL037274.

Griffies, S. M., Biastoch, A., Böning, C., Bryan, F., Danabasoglu, G., Chassignet, E. P., England, M. H., Gerdes, R., Haak, H., Hallberg, R. W., 
Hazeleger, W., Jungclaus, J., Large, W. G., Madec, G., Pirani, A., Samuels, B. L., Scheinert, M., Gupta, A. S., Severijns, C. A., Simmons, H. L., Tregier, A. M., Winton, M., Yeager, S., Yin, J., 2009. Coordinated ocean-ice reference experiments (COREs). Ocean Mod. 26, 1-46.

Holland, M. M., Bitz, C. M., Hunke, E. C., Lipscomb, W. H., Schramm, J. L., 2006. Influence of the sea ice thickness distribution on polar climate in CCSM3. J. Clim. 19, 2398-2414.

Holland, M. M., Serreze, M. C., Stroeve, J., 2008. The sea ice mass budget of the Arctic and its future change as simulated by coupled climate models. Clim. Dyn. 34, 185-200.

Hunke, E., Holland, M., 2007. Global atmospheric forcing data for Arctic ice-ocean modeling. J. Geophys. Res. 112, C06S14, doi:10.1029/2006JC003640.

Hunke, E. C., 2001. Viscous-plastic sea ice dynamics with the EVP model: Linearization issues. J. Comput. Phys. 170, 18-38.

Hunke, E. C., 2010. Thickness sensitivities in the CICE sea ice model. Ocean Mod. 34, 137-149, doi:10.1016/j.ocemod.2010.05.004.

Hunke, E. C., 2014. Weighing the importance of surface forcing on sea ice - a September 2007 modeling study. Q. J. Roy. Met. Soc., published online, DOI:10.1002/qj.2353.

Hunke, E. C., Bitz, C. M., 2009. Age characteristics in a multidecadal arctic sea ice simulation. J. Geophys. Res. 114, C08013, doi:10.1029/2008JC005186. 
Hunke, E. C., Dukowicz, J. K., 1997. An elastic-viscous-plastic model for sea ice dynamics. J. Phys. Oceanogr. 27, 1849-1867.

Hunke, E. C., Dukowicz, J. K., 2002. The Elastic-Viscous-Plastic sea ice dynamics model in general orthogonal curvilinear coordinates on a sphereEffect of metric terms. Mon. Wea. Rev. 130, 1848-1865.

Hunke, E. C., Hebert, D. A., Lecomte, O., 2013a. Level-ice melt ponds in the Los Alamos Sea Ice Model, CICE. Ocean Mod. 71, 26-42.

Hunke, E. C., Lipscomb, W. H., Turner, A. K., Jeffery, N., Elliott, S., 2013b. CICE: the Los Alamos Sea Ice Model, Documentation and Software User's Manual, version 5.0. Tech. Rep. LA-CC-06-012, Los Alamos National Laboratory, Los Alamos, New Mexico.

Hunke, E. C., Notz, D., Turner, A. K., Vancoppenolle, M., 2011. The multiphase physics of sea ice: a review for model developers. The Cryosphere 5, 989-1009.

Kurtz, N., Studinger, M., Harbeck, J., Onana, V., Farrell, S., 2009. IceBridge Sea Ice Freeboard, Snow Depth, and Thickness. NASA Distributed Active Archive Center at the National Snow and Ice Data Center, Boulder, CO, digital media.

URL http://nsidc.org/data/idcsi2.html

Kwok, R., Cunningham, G. F., 2008. ICESat over Arctic sea ice: Estimation of snow depth and ice thickness. J. Geophys. Res. 113, C08010, doi:10.1029/2008JC004753. 
Kwok, R., Cunningham, G. F., Wensnahan, M., Rigor, I., Zwally, H. J., Yi, D., 2009. Thinning and volume loss of the Arctic Ocean sea ice cover: 2003-2008. J. Geophys. Res. 114, C07005, doi:10.1029/2009JC005312.

Kwok, R., Cunningham, G. F., Zwally, H. J., Yi, D., 2007. Ice, Cloud, and land Elevation Satellite (ICESat) over Arctic sea ice: Retrieval of freeboard. J. Geophys. Res. 112, C12013, doi:10.1029/2006JC003978.

Kwok, R., Untersteiner, N., 2011. The thinning of Arctic sea ice. Phys. Today April, 36-41.

Large, W. G., Yeager, S. G., 2009. The global climatology of an interannually varying air-sea flux data set. Clim. Dyn. 33, 341-364.

Lietaer, O., Deleersnijder, E., Fichefet, T., Vancoppenolle, M., Comblen, R., Bouillon, S., Legat, V., 2011. The vertical age profile in sea ice: Theory and numerical results. Ocean Mod. 40, 211-226.

Lindsay, R., 2010. New Unified Sea Ice Thickness Climate Data Record. Eos, Trans. Amer. Geophys. Union 91, 405-406.

Lindsay, R., 2013. Unified Sea Ice Thickness Climate Data Record Collection Spanning 1947-2012. National Snow and Ice Data Center, Boulder, CO, digital media.

URL http://dx.doi .org/10.7265/N5D50JXV

Lindsay, R. W., Zhang, J., Schweiger, A., Steele, M., Stern, H., 2009. Arctic sea ice retreat in 2007 follows thinning trend. J. Clim. 22, 165-176, doi:10.1175/2008JCLI2521.1. 
Lipscomb, W. H., 2001. Remapping the thickness distribution in sea ice models. J. Geophys. Res.-Oceans 106, 13,989-14,000.

Lipscomb, W. H., Hunke, E. C., Maslowski, W., Jakacki, J., 2007. Improving ridging schemes for high-resolution sea ice models. J. Geophys. Res.Oceans 112, C03S91, doi:10.1029/2005JC003355.

Maslanik, J. A., Fowler, C., Stroeve, J., Drobot, S., Zwally, J., Yi, D., Emery, W., 2007. A younger, thinner Arctic ice cover: Increased potential for rapid, extensive sea-ice loss. Geophys. Res. Lett. 34, L24501, doi:10.1029/2007GL032043.

Maslanik, J. A., Stroeve, J., Fowler, C., Emery, W., 2011. Distribution and trends in arctic sea ice age through spring 2011. Geophys. Res. Lett. 38, L13502, doi:10.1029/2011GL047735.

Maykut, G. A., Perovich, D. K., 1987. The role of shortwave radiation in the summer decay of a sea ice cover. J. Geophys. Res. 92(C7), 7032-7044.

Melling, H., Riedel, D., 2008. Ice Draft and Ice Velocity Data in the Beaufort Sea, 1990-2003. National Snow and Ice Data Center, Boulder, CO, digital media.

National Snow and Ice Data Center, 1998, updated 2006. Submarine Upward Looking Sonar Ice Draft Profile Data and Statistics. National Snow and Ice Data Center/World Data Center for Glaciology, Boulder, CO, digital media. 
Pettipas, R., Prinsenberg, S. J., 2008. Moored current meter and CTD observations from Barrow Strait, 2003-2004. Can. Data Rep. Hydrogr. Ocean Sci. 173,134 p.

Prinsenberg, S. J., Pettipas, R., 2008. Ice and ocean mooring data statistics from Barrow Strait, the central section of the NW Passage in the Canadian Arctic Archipelago. Int. J. Offshore Pol. Eng., 18(4), 277-281.

Rothrock, D. A., 1975. The energetics of the plastic deformation of pack ice by ridging. J. Geophys. Res. 80, 4514-4519.

Schweiger, A., Lindsay, R. W., Zhang, J., Steele, M., Stern, H., Kwok, R., 2011. Uncertainty in modeled Arctic sea ice volume. J. Geophys. Res. 116, C00D06, doi:10.1029/2011JC007084.

Screen, J. A., 2013. Influence of Arctic sea ice on European summer precipitation. Environ. Res. Lett. 8, 044015 doi:10.1088/1748-9326/8/4/044015.

Steele, M., 1992. Sea ice melting and floe geometry in a simple ice-ocean model. J. Geophys. Res. 97(C11), 17729-17738.

Stroeve, J. C., Serreze, M. C., Holland, M. M., Kay, J. E., Masklanik, J., Barrett, A. P., 2012. The Arctic's rapidly shrinking sea ice cover: a research synthesis. Clim. Change 110, 1005-1027.

Thorndike, A. S., Rothrock, D. A., Maykut, G. A., Colony, R., 1975. The thickness distribution of sea ice. J. Geophys. Res. 80, 4501-4513.

Tsamados, M., Feltham, D. L., Schroeder, D., Flocco, D., Farrell, S. L., Kurtz, N. T., Laxon, S. W., Bacon, S., 2014. Impact of variable atmo- 
spheric and oceanic form drag on simulations of Arctic sea ice. J. Phys. Oceanogr. 44, 1329-1353.

Tsamados, M., Feltham, D. L., Wilchinsky, A. V., 2013. Impact of a new anisotropic rheology on simulations of arctic sea ice. J. Geophys. Res. Oceans 118, 91-107.

URL http://dx.doi .org/10.1029/2012JC007990

Tschudi, M. A., Fowler, C., Maslanik, J. A., Stroeve, J., 2010. Tracking the movement and changing surface characteristics of arctic sea ice. IEEE J. Selected Topics in Earth Obs. And Rem. Sens.

Turner, A. K., Hunke, E. C., Bitz, C. M., 2013. Two modes of sea-ice gravity drainage: a parameterization for large-scale modeling. J. Geophys. Res. 118, 2279-2294, doi:10.1002/jgrc.20171.

Vancoppenolle, M., Fichefet, T., Goosse, H., 2009a. Simulating the mass balance and salinity of arctic and antarctic sea ice. 2. Importance of sea ice salinity variations. Ocean Mod. 27, 54-69.

Vancoppenolle, M., Fichefet, T., Goosse, H., Bouillon, S., Madec, G., Maqueda, M. A. M., 2009b. Simulating the mass balance and salinity of arctic and antarctic sea ice. 1. Model description and validation. Ocean Mod. 27, 33-53.

Wilchinsky, A. V., Feltham, D., 2006. Modelling the rheology of sea ice as a collection of diamond-shaped floes. J. Non-Newtonian Fluid Mech. 138, $22-32$. 
778 Witte, H., Fahrbach, E., 2005. AWI Moored ULS Data, Greenland Sea and 779 Fram Strait, 1991-2002. National Snow and Ice Data Center, Boulder, CO, 780 digital media.

781 Zhang, J., Rothrock, D., 2003. Modeling global sea ice with a thickness and 782 enthalpy distribution model in generalized curvilinear coordinates. Mon. 783 Wea. Rev. 131, 845-861. 


\begin{tabular}{cccccc}
\hline category & CNTL & STD 10 & WMO 5 & WMO 5+ & WMO 6 \\
\hline 1 & 0.00 & 0.00 & 0.00 & 0.00 & 0.00 \\
2 & 0.64 & 0.32 & 0.30 & 0.30 & 0.15 \\
3 & 1.39 & 0.66 & 0.70 & 0.70 & 0.30 \\
4 & 2.47 & 1.03 & 1.20 & 1.20 & 0.70 \\
5 & 4.57 & 1.47 & 2.00 & 2.00 & 1.20 \\
6 & & 2.01 & & 4.57 & 2.00 \\
7 & & 2.73 & & & \\
8 & & 3.78 & & & \\
9 & & 5.36 & & & \\
10 & & 7.74 & & & \\
\hline
\end{tabular}

Table 1: Lower boundary values for thickness categories (m). 


\begin{tabular}{|c|c|c|c|c|}
\hline label & $\mathrm{N}_{c a t}$ & ITD & years & description \\
\hline \multirow[t]{5}{*}{ CNTL } & 5 & standard & $1958-2009$ & $a^{*}=0.5$ \\
\hline & & & & form drag parameterization $\mathrm{OFF}$ \\
\hline & & & & elastic-viscous-plastic dynamics \\
\hline & & & & 7 vertical layers \\
\hline & \multicolumn{4}{|c|}{ Physical Parameterizations } \\
\hline astar & 5 & standard & 1990-2009 & $a^{*}=0.1$ \\
\hline formdrag & 5 & standard & 1990-2009 & form drag parameterization $\mathrm{ON}$ \\
\hline aniso & 5 & standard & 1990-2009 & elastic-anisotropic-plastic (EAP) dynamics \\
\hline aniso+formdrag & 5 & standard & $1990-2009$ & EAP and form drag parameterizations ON \\
\hline \multirow[t]{2}{*}{ halfU } & 5 & standard & 1990-2009 & $0.5 \mathbf{U}_{i}$ applied for horizontal transport \\
\hline & \multicolumn{4}{|c|}{ Vertical Resolution } \\
\hline 4lyr & 5 & standard & 1958-2009 & 4 vertical layers \\
\hline \multicolumn{5}{|c|}{ Thickness Category Resolution } \\
\hline STD 10 & 10 & standard & $1958-2009$ & as CNTL but with 10 categories \\
\hline WMO 5 & 5 & WMO & $1958-2009$ & World Meteorological Organization categories \\
\hline WMO $5+$ & 6 & WMO & $1958-2009$ & same as WMO5 plus one thick category \\
\hline WMO 6 & 6 & WMO & $1958-2009$ & same as WMO5 plus one thin category \\
\hline
\end{tabular}

Table 2: Control and sensitivity simulations. $N_{c a t}$ is the number of ice thickness distribution (ITD) categories. The standard ITD is given by Eq. 1; see Table 1 and Fig. 3 for category boundary values. 


\begin{tabular}{|c|c|c|c|c|c|c|c|}
\hline Data Source & Data & CNTL & astar & formdrag & STD 10 & WMO 5 & WMO $5+$ \\
\hline Submarines $^{a}$ & 2.52874 & 2.31325 & 1.97063 & 2.15990 & 2.52277 & 1.95785 & 2.26214 \\
\hline Airborne $^{\dagger b}$ & 3.13818 & 3.58993 & 3.07307 & 3.09780 & 3.96628 & 2.95049 & 3.48772 \\
\hline Coastal $^{\dagger c}$ & 1.34916 & 5.39137 & 4.14398 & 3.73605 & 6.26804 & 3.91331 & 5.41778 \\
\hline Moorings & 1.38138 & 1.72851 & 1.63750 & 1.57504 & 1.88735 & 1.34602 & 1.71345 \\
\hline $\mathrm{BGEP}^{d}$ & 1.53632 & 2.08128 & 1.70255 & 1.79518 & 2.25713 & 1.59307 & 1.97489 \\
\hline $\mathrm{NPEO}^{e}$ & 2.88623 & 1.78872 & 1.55387 & 1.61870 & 2.02563 & 1.69882 & 1.80673 \\
\hline IOS-EBS $^{f}$ & 1.29336 & 1.66659 & 1.72068 & 1.010301 & 1.81412 & 1.28048 & 1.10000 \\
\hline IOS-CHK ${ }^{g}$ & 1.19654 & 1.92455 & 1.45411 & 1.54079 & 2.09728 & 1.31790 & 1.79942 \\
\hline AWI-GS ${ }^{h}$ & 1.02940 & 1.27805 & 1.39385 & 1.31636 & 1.37537 & 1.11209 & 1.26467 \\
\hline BIO-LS ${ }^{i}$ & 0.879722 & 2.55032 & 2.39715 & 2.81366 & 2.98289 & 1.18660 & 2.58016 \\
\hline Davis $\mathrm{St}^{j}$ & 0.762295 & 1.06866 & 1.13605 & 0.877247 & 1.16990 & 0.943930 & 1.06779 \\
\hline All data & 1.98030 & 2.27632 & 1.98355 & 2.02528 & 2.50613 & 1.84068 & 2.24381 \\
\hline
\end{tabular}

Table 3: Sea ice draft ( ${ }^{\dagger}$ thickness) measurements (m) from observations (Lindsay, 2013) and selected model simulations for grid cells containing the observation locations (see Fig. 6), for 1990-2009. Bold font indicates model output is thinner than the observations. ${ }^{a}$ National Snow and Ice Data Center (1998, updated 2006). ${ }^{b}$ Kurtz et al. (2009) ${ }^{c}$ Canadian Ice Thickness Program. ${ }^{d}$ The data were collected and made available by the Beaufort Gyre Exploration Project based at the Woods Hole Oceanographic Institution (http://www.whoi.edu/beaufortgyre). ${ }^{e}$ North Pole Environmental Observatory. ${ }^{f}$ Melling and Riedel (2008). ${ }^{g}$ IOS Chukchi Sea. ${ }^{h}$ Witte and Fahrbach (2005). ${ }^{i}$ Prinsenberg and Pettipas (2008); Pettipas and Prinsenberg (2008). ${ }^{j}$ R. E. Moritz, Davis Strait Freshwater Flux Array, NSF Grant OPP-02300381. 


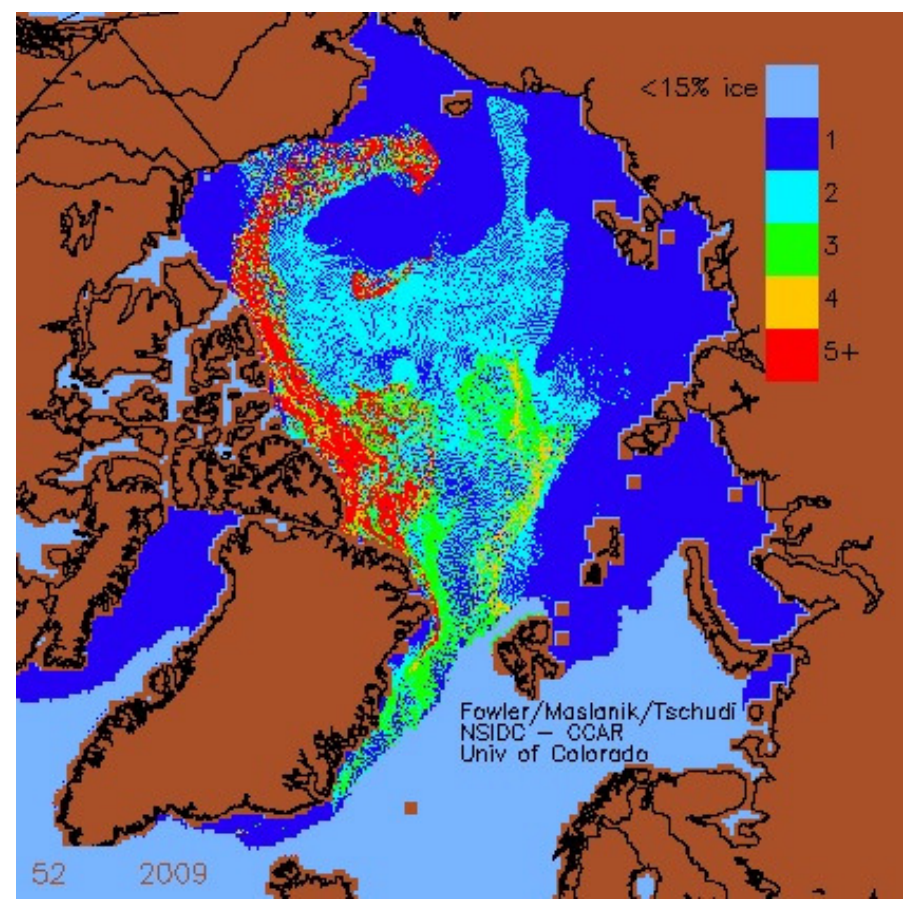

Figure 1: Satellite derived estimate of Arctic sea ice age (years) for week 52 of 2009, courtesy of C. Fowler, J. Maslanik, and M. Tschudi, Dept. of Aerospace Engr., University of Colorado, Boulder CO. 


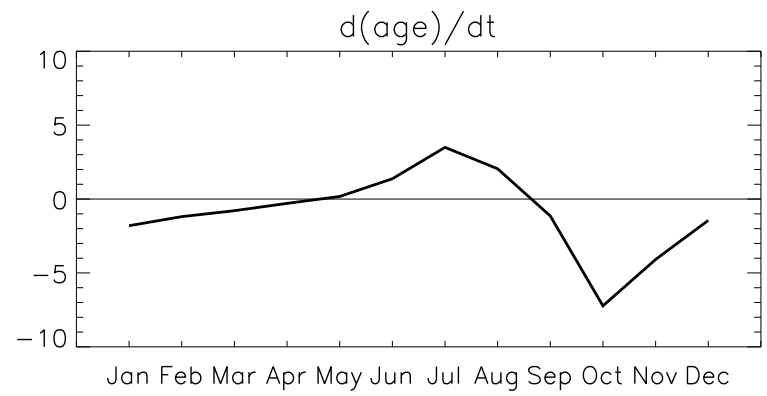

Figure 2: Derivative of sea ice age with respect to time (days per day), averaged for 19902009 over Arctic grid cells with ice concentration greater than 50\%, from the control run (CNTL). Chronological aging is not included in the derivative.

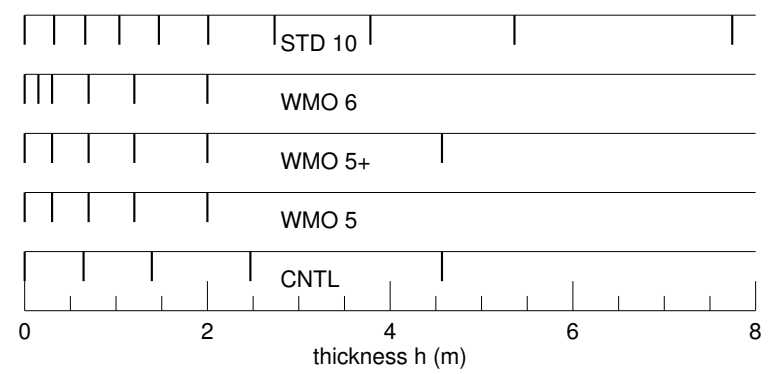

Figure 3: Category boundaries for the ITD resolution study in section 5. 

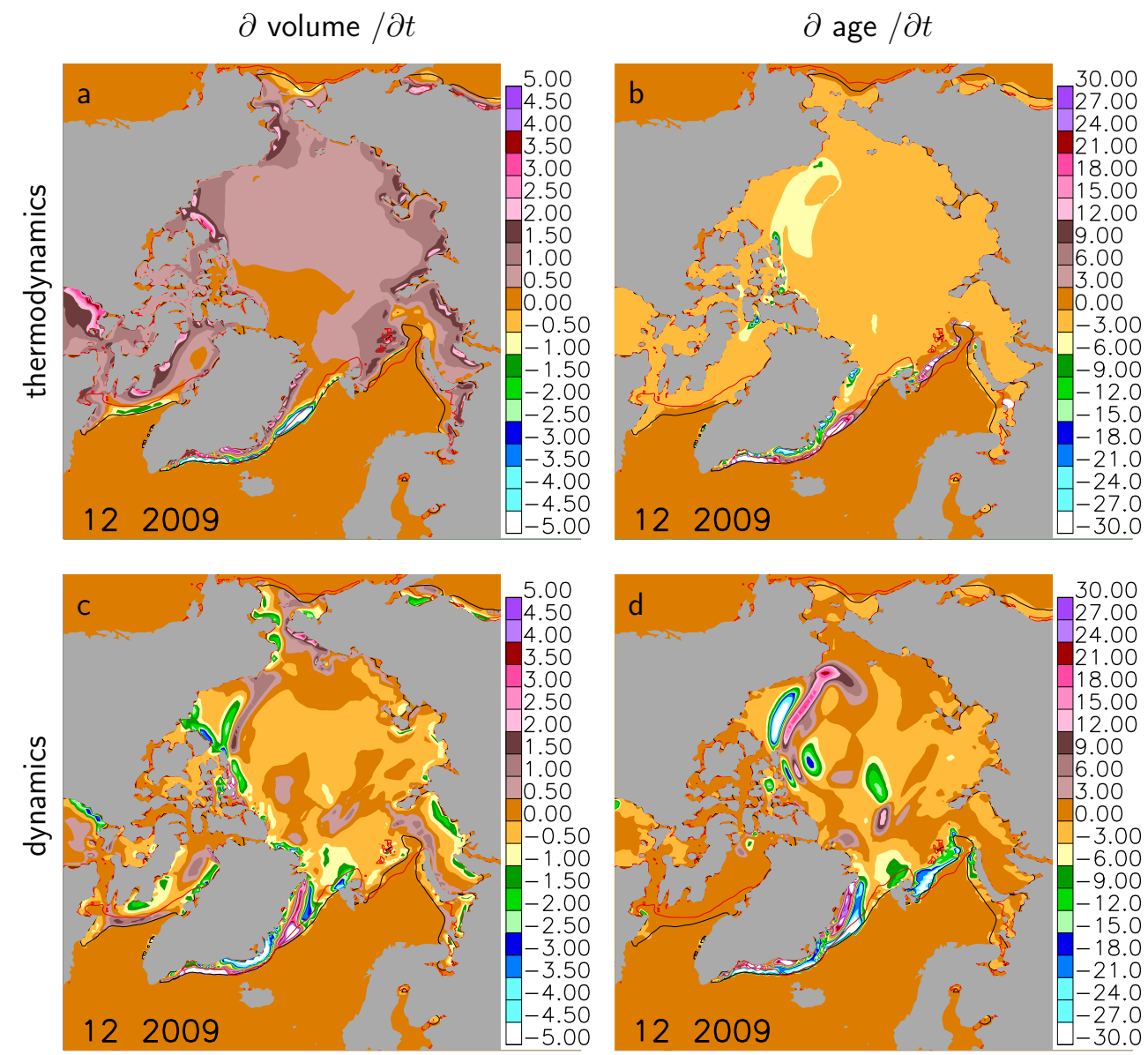

Figure 4: Derivatives with respect to time of sea ice volume (left, cm/day) and age (right, days per day), due to (top) thermodynamic and (bottom) dynamical processes, from the control run. Chronological aging is not included. The black contour represents $15 \%$ ice concentration, and the red line is the $15 \%$ concentration contour from passive microwave satellite data (Cavalieri et al., 1996, updated 2009). 
ICESat
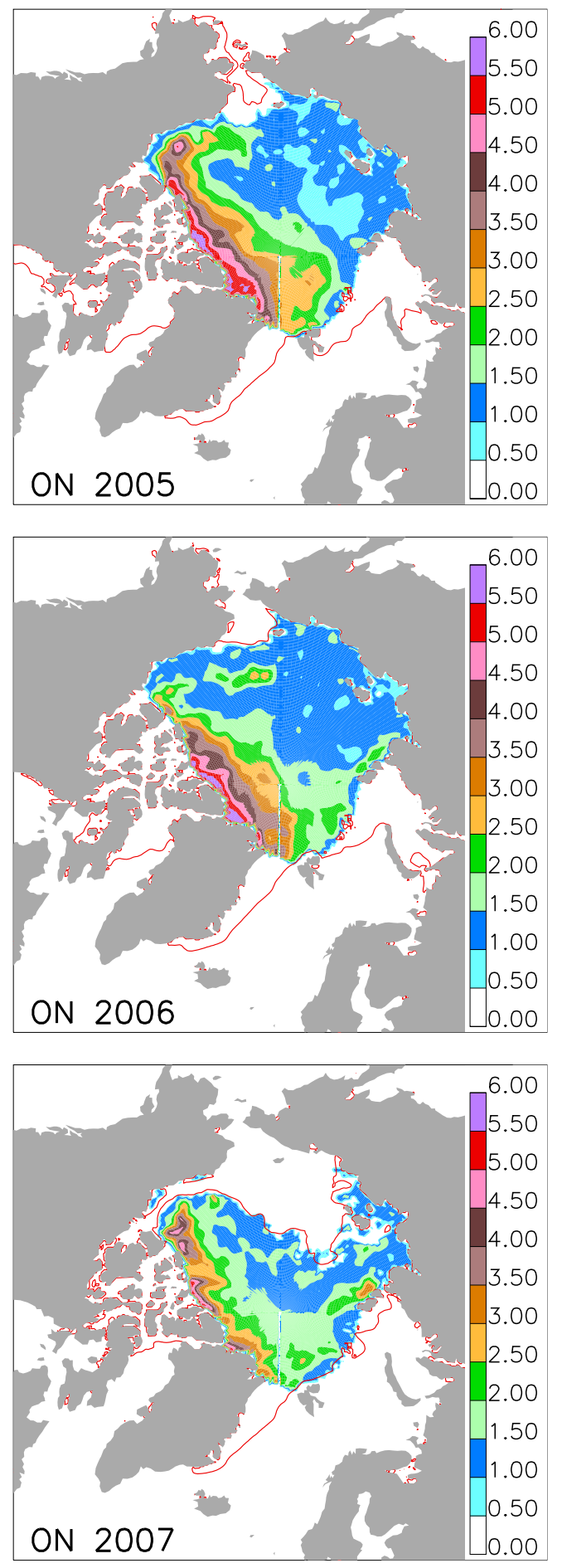

CNTL
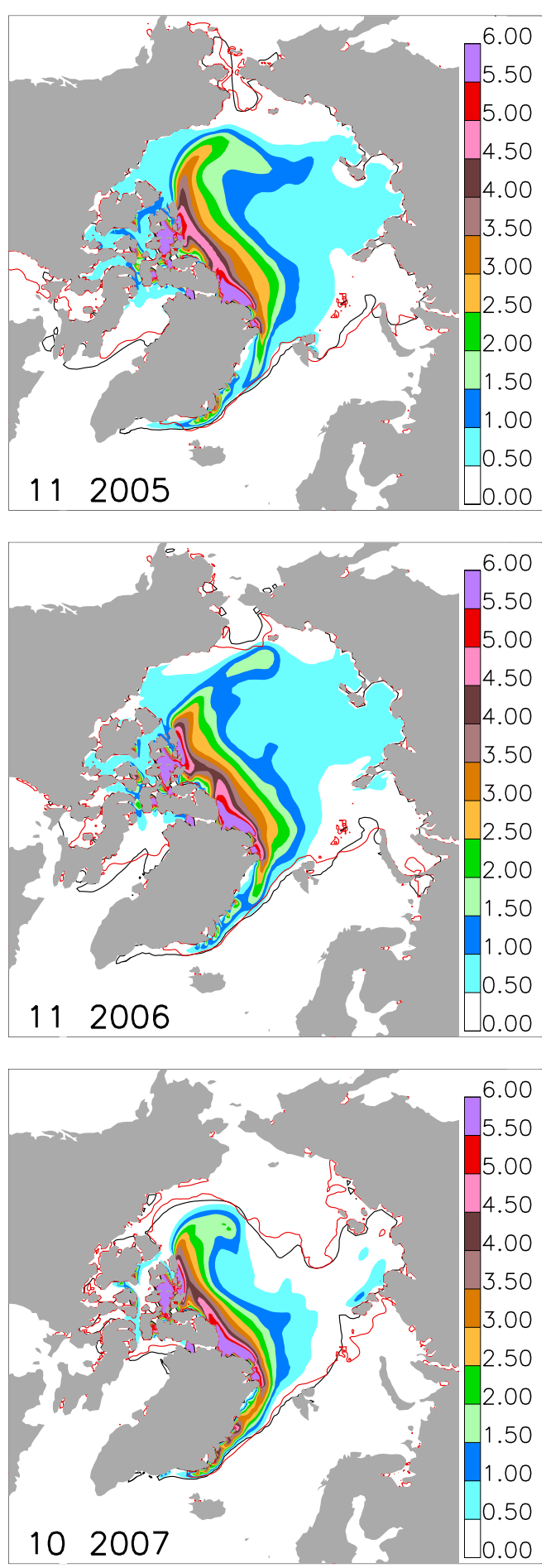

Figure 5: (left) Sea ice thickness estimates (m) from ICESat for October/November 20052007, compared with (right) model output from the control run for each year. ICESat periods covered Oct 21-Nov 24, 2005, Oct 25-Nov 27, 2006, and Oct 2-Nov 5, 2007. The black contour represents $15 \%$ model ice concentration, and the red line is the $15 \%$ concentration contour from passive microwave satellite data (Cavalieri et al., 1996, updated 2009). Missing ICESat data are shown as zero values here. 


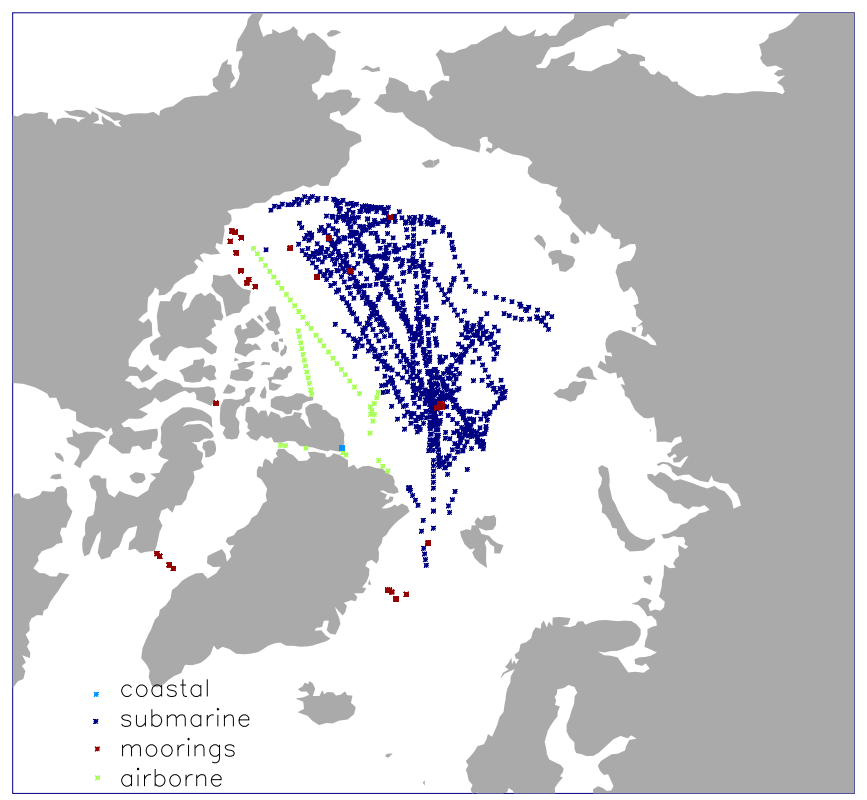

Figure 6: Locations and types of data used for the comparison in Table 3 (Lindsay, 2013). Data points coinciding with land grid cells in the model were not used. 

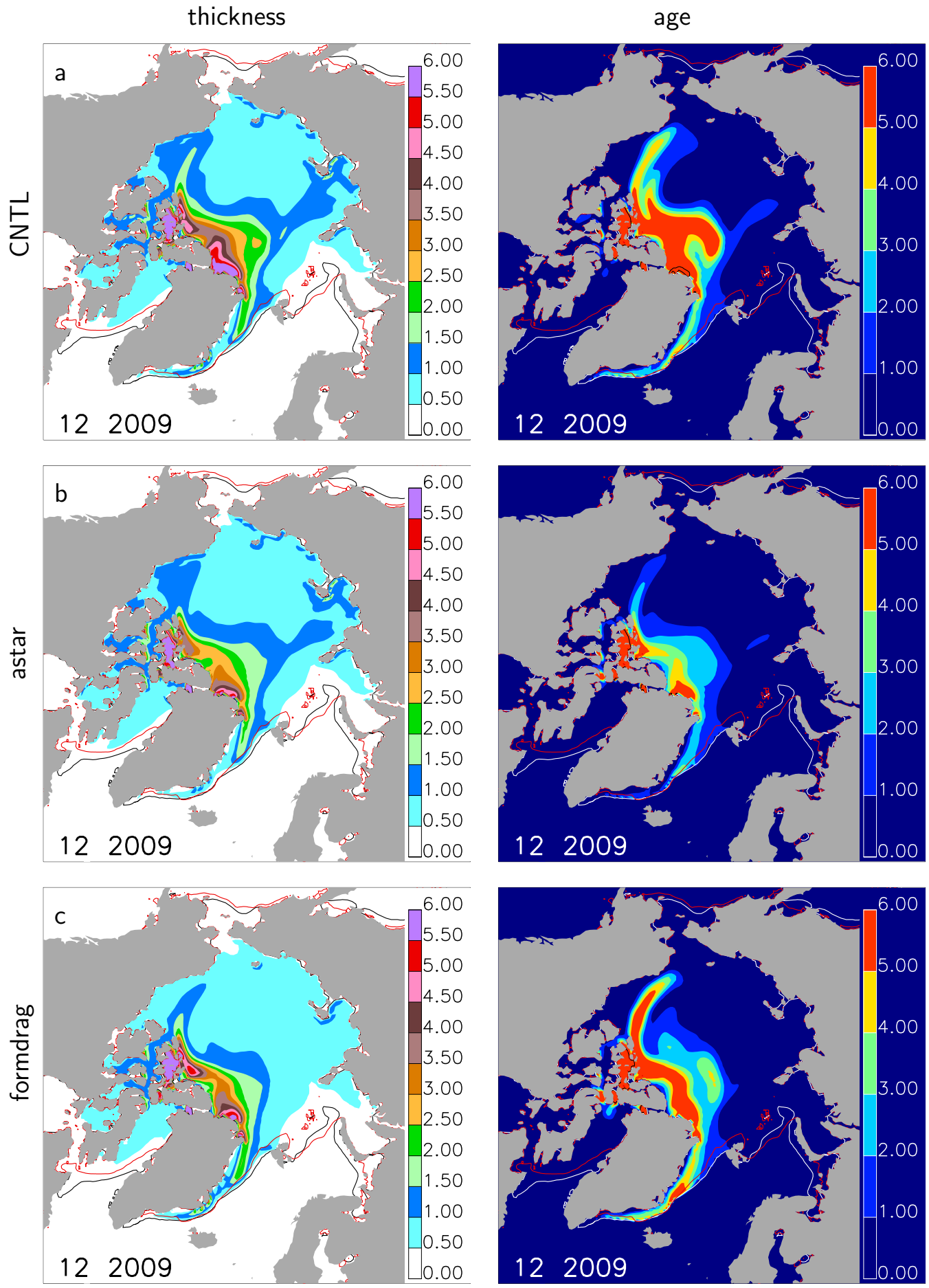

Figure 7: Sea ice model thickness (left, m) and age (right, years) for the (a) CNTL, (b) astar and (c) formdrag simulations. The black (left) and white (right) lines are the $15 \%$ ice concentration contours from the model, and the red lines are the $15 \%$ concentration contours from passive microwave satellite data (Cavalieri et al., 1996, updated 2009). Black age contours encompass ice older than 10 yetts. 

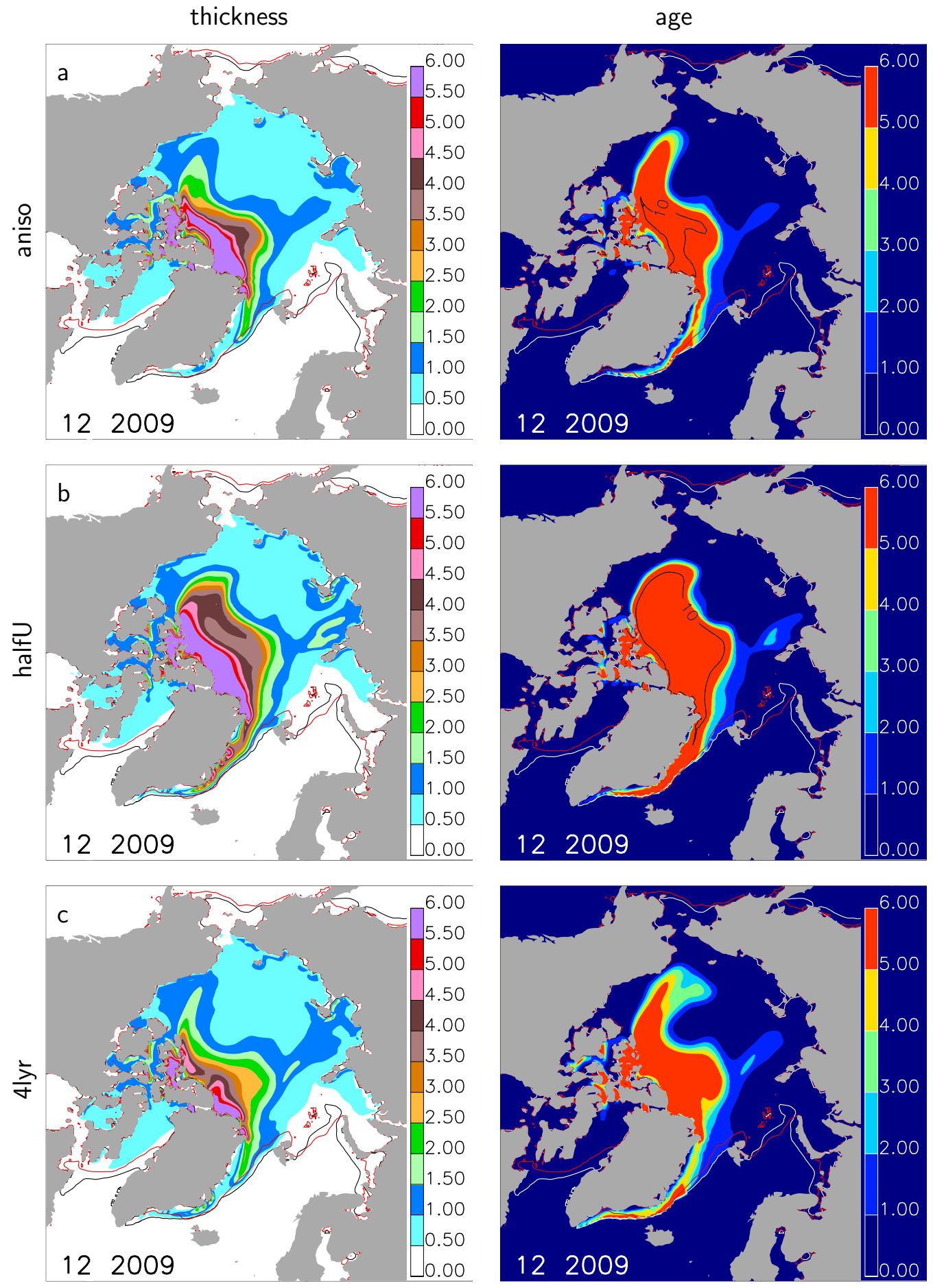

Figure 8: As in Fig. 7 for the (a) anisotropic, (b) halfU and (c) 4-layer sensitivity tests. 

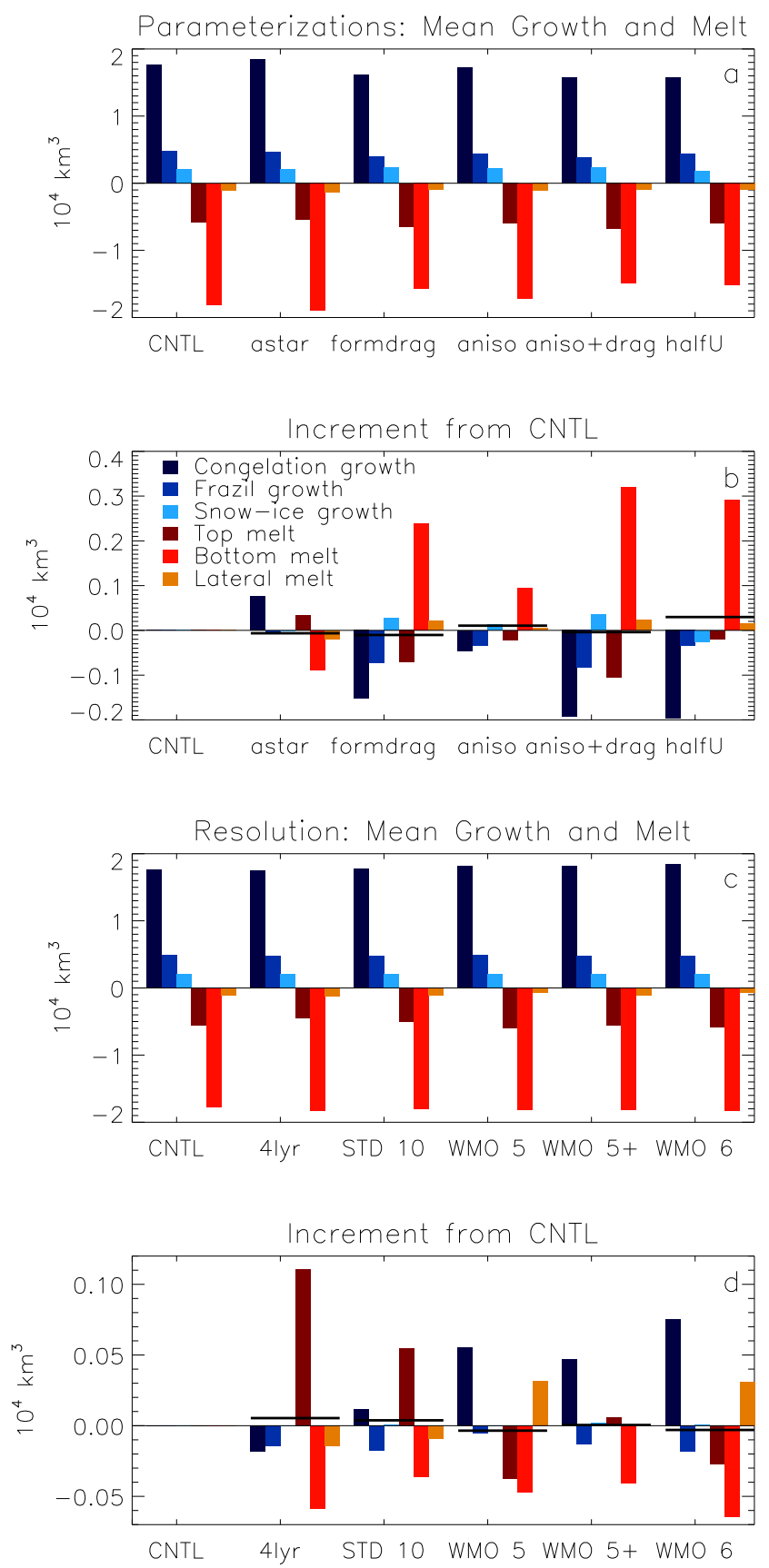

Figure 9: Mean annual volume of ice gained or lost through thermodynamic processes associated with (a) parameterization options for 1990-2009 and (c) resolution tests for 1958-2009. The incremental differences fr $\$$ ne the control run volume for each process are shown in (b) and (d); e.g., positive melt terms indicate increased ice volume due to decreased melting, relative to CNTL. Horizontal black lines represent the net change in volume from the control run for all processes. Note the differing scales in (b) and (d). 


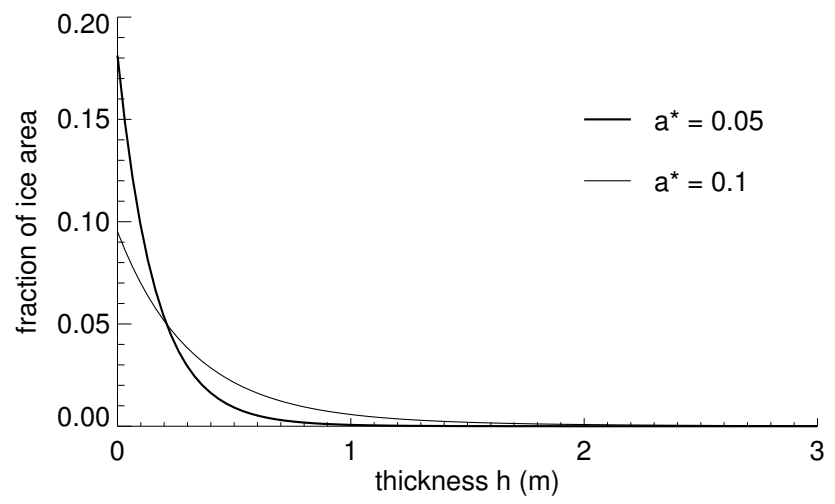

Figure 10: Participation function for two values of the parameter $a^{*}$, which represents the mean cumulative area fraction of ice participating in the ridging process. These participation functions assume a uniform cumulative ice thickness distribution with 100 STD categories (lower boundary of thickest category is $12.67 \mathrm{~m}$ ). 

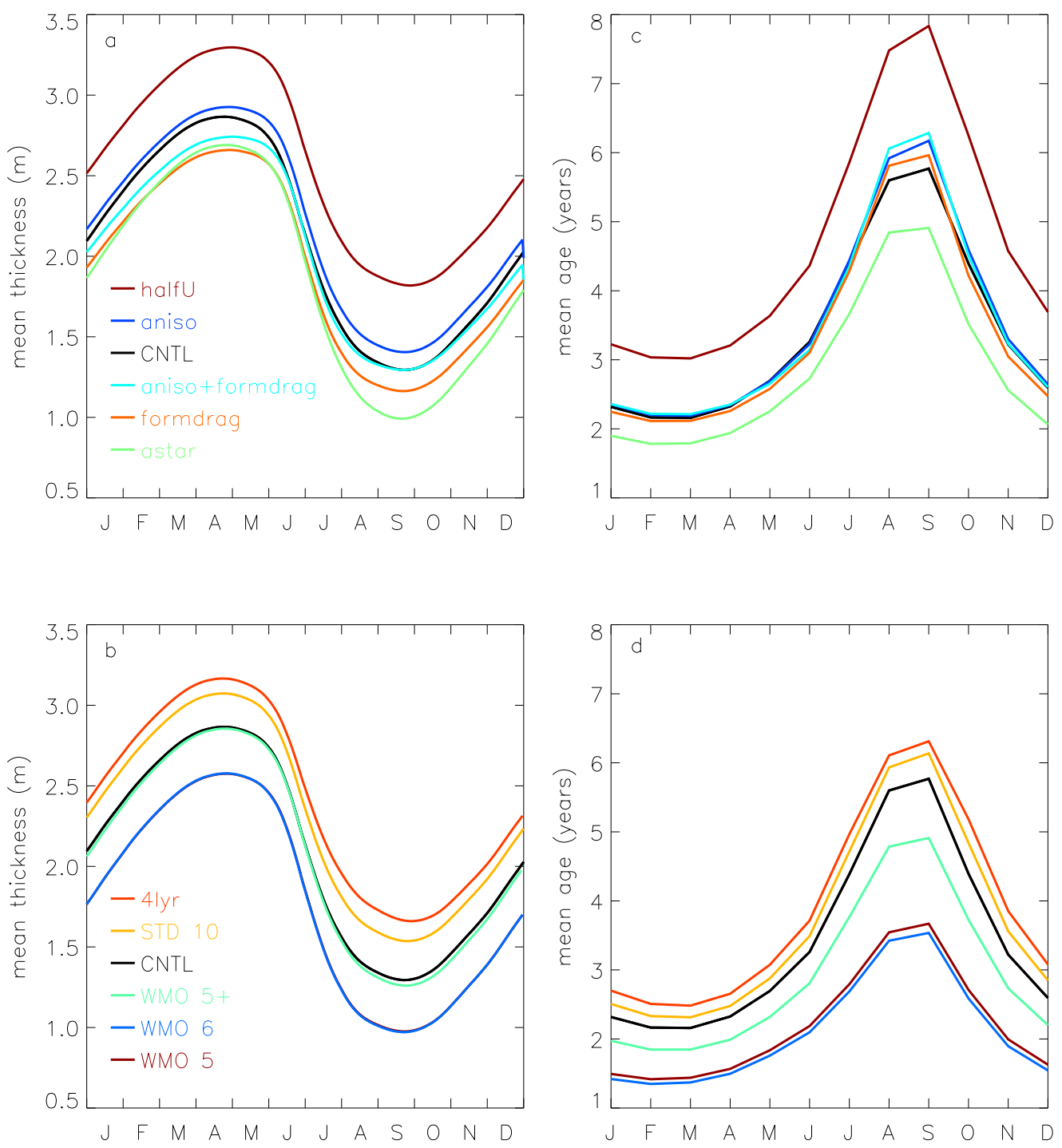

Figure 11: Mean annual cycle of sea ice (left) thickness and (right) age for the control run and (a, c) 5 physical parameterization tests and (b, d) 5 resolution tests for 19902009. Thickness output is plotted from daily model diagnostics, while age is plotted using monthly history files. 

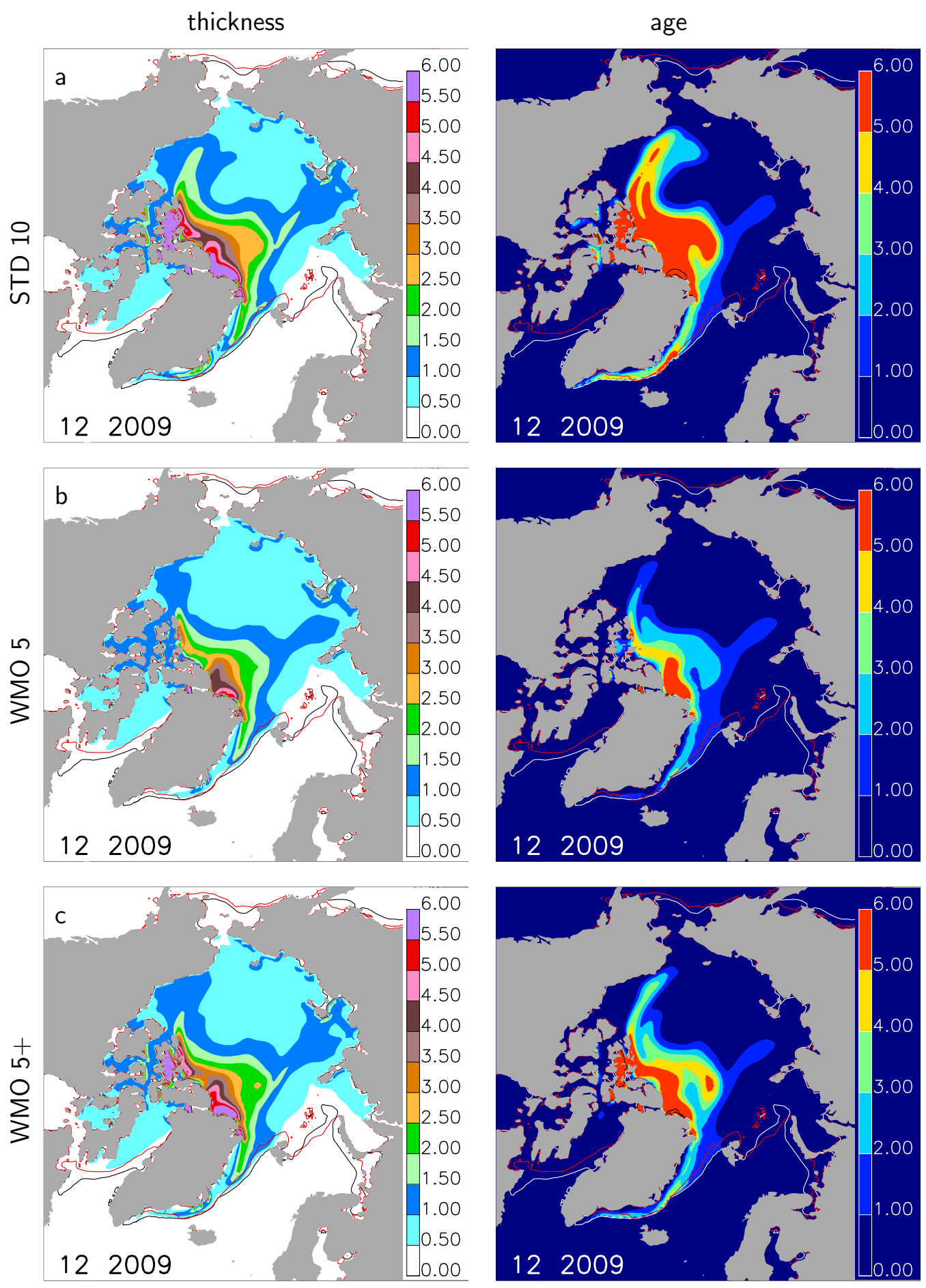

Figure 12: As in Fig. 7 for the (a) STD 10, (b) WMO 5 and (c) WMO 5+ ice thickness distribution discretizations. 

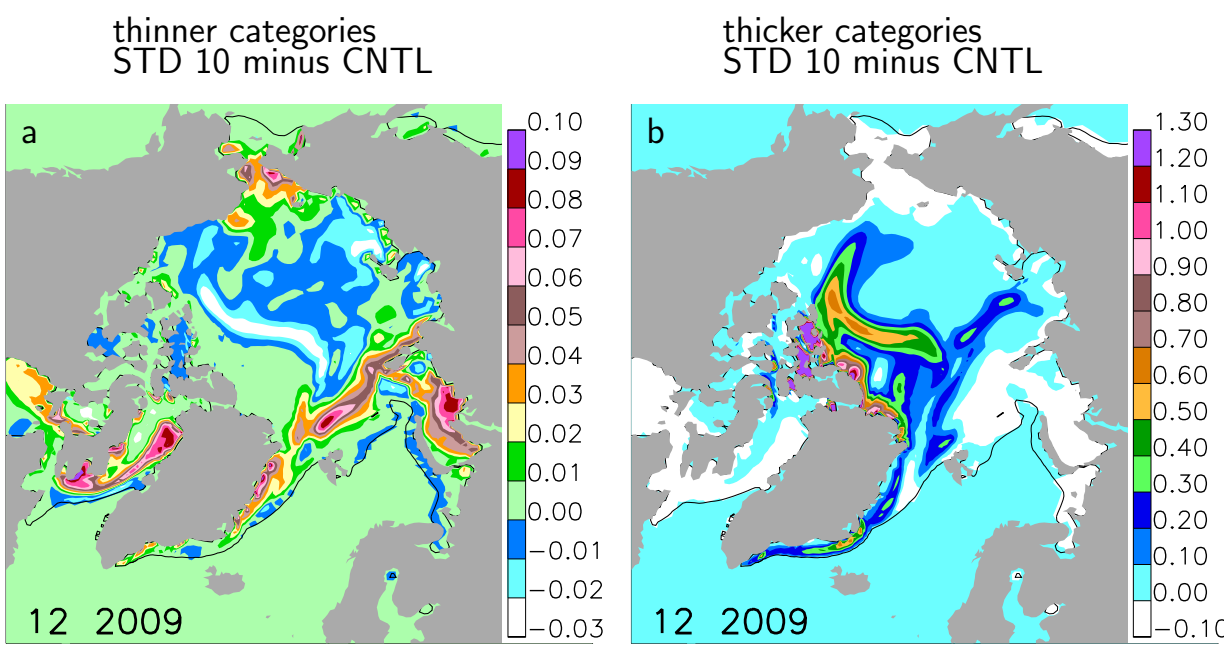

WMO 5+ minus CNTL

WMO $5+$ minus WMO 5
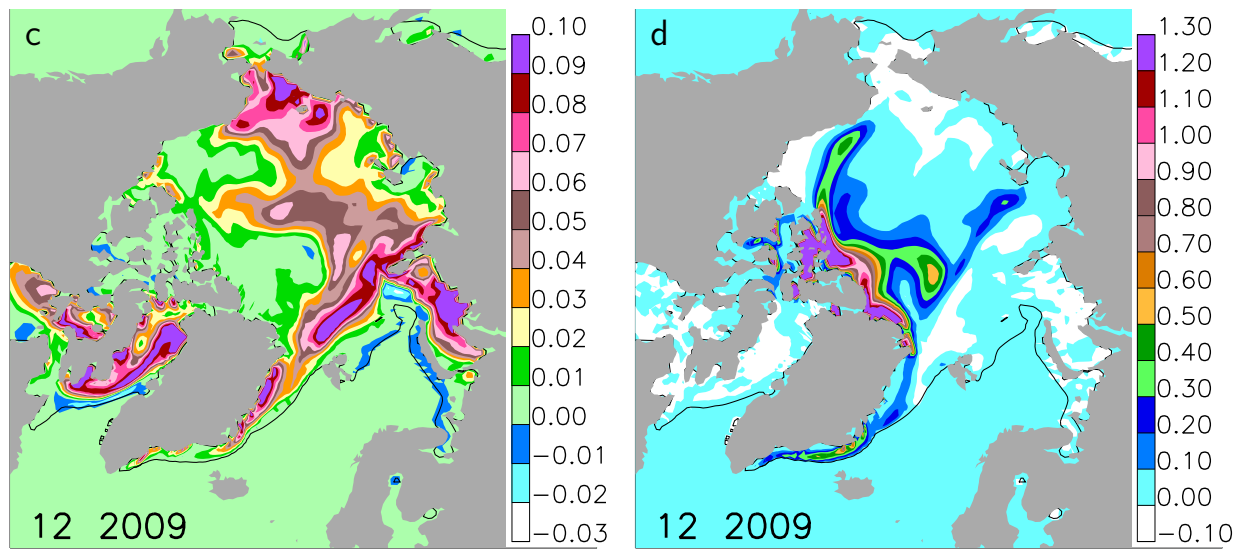

Figure 13: Difference in mean thickness $(\mathrm{m})$ for (left) thinner and (right) thicker categories for (a, b) STD minus CNTL, (c) WMO 5+ minus CNTL and (d) WMO 5+ minus WMO 5. "Thinner" means category 1 in CNTL (up to $0.64 \mathrm{~m}$ ) and the sum of categories 1 and 2 in STD 10 (up to $0.66 \mathrm{~m}$ ), WMO 5 and WMO 5+ (up to $0.70 \mathrm{~m}$ ); the remaining ice is "thicker". Black contours trace the $15 \%$ ice concentration in the control. Differences are taken only in grid cells where the ice area fraction in both simulations is greater than $15 \%$. Note the difference in scales. 